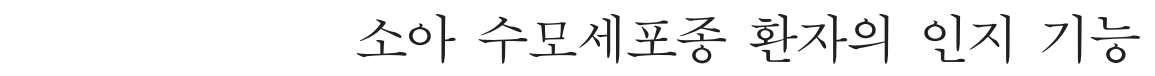

\author{
오주용 $^{1)} \cdot$ 김지혜 $^{1)} \cdot$ 김빛나 $^{1)} \cdot$ 안경진 $^{1)} \cdot$ 성기웅 $^{2)} \cdot$ 정유숙 ${ }^{1)}$ \\ 성균관대학교 의과대학 삼성서울병원 정신과학교실, ${ }^{1)}$ 성균관대학교 의과대학 삼성서울병원 소아청소년과학교실2)
}

\title{
Cognitive Functions in Children Treated for Medulloblastoma
}

\author{
Ju Yong Oh, M.A. ${ }^{1}$, Ji-Hae Kim, Ph.D. ${ }^{1)}$, Binna Kim, M.A. ${ }^{1)}$, \\ Kyung Jin An, M.D. ${ }^{1)}$, Ki Woong Sung, M.D., Ph.D.' and Yoo Sook Joung, M.D., Ph.D. ${ }^{1)}$ \\ ${ }^{1)}$ Department of Psychiatry, Samsung Medical Center, Sungkyunkwan University School of Medicine, Seoul, Korea \\ ${ }^{2)}$ Department of Pediatrics, Samsung Medical Center, Sungkyunkwan University School of Medicine, Seoul, Korea
}

Objectives : To investigate the cognitive functions of pediatric cancer patients and to test the hypotheses that the impairment of processing speed and working memory are more prevalent in children with medulloblastoma (MBL) compared to children with neuroblastoma (NBL).

Methods : We gave the Korean version of the Wechsler Intelligent Scale for Children-III to 21 children with MBL and 24 children with NBL during outpatient follow-up after the treatment was completed.

Results : Children with MBL showed below average performance across most of the sub-tests. The full scale IQ, verbal IQ, and performance IQ of children with MBL were significantly lower than those of children with NBL. There were significant differences between two groups in coding and Digit Span subtest scores. Children with MBL performed especially poorly in the coding subtest.

Conclusion : These findings support previous reports of generally low IQ and the dysfunction of processing speed and working memory among children with MBL, a kind of central nervous system tumor. Further investigation is needed to determine how the deficit of processing speed and working memory affect neurocognitive development and general intelligent functions.

KEY WORDS : Pediatric Cancer · Cognitive Function · Processing Speed · Working Memory · Medulloblastoma · Neuroblastoma.

\section{서 론}

의학의 발전에 힘입어 소아암 환자의 5 년 생존율이 최대 $80 \%$ 까지 향상됨에 따라 치료 이후의 적응에 대한 관심이 고 조되고 있다. ${ }^{1)}$ 소아암 환자들은 치료가 종결된 이후에도 신체 적, 정서적, 인지적 측면에서 어려움을 경험하는 것으로 나타났 다. ${ }^{2}$ 이 가운데 인지 기능은 학업 성취와 관련되며, 직업 선택 과 성인기의 전반적인 삶의 질에 이르는 장기적인 영향을 미치 는 것으로 알려져 있다. ${ }^{3)}$ 이에 소아암 환자들이 경험할 수 있

접수완료 :2011년 9월 21일 / 심사완료 :2011년 11월 14일

Address for correspondence:Yoo Sook Joung, M.D., Ph.D., Department of Psychiatry, Samsung Medical Center, Sungkyunkwan University School of Medicine, 50 Irwon-dong, Gangnam-gu, Seoul 135-710, Korea

Tel : +82.2-3410-3589. Fax : +82.2-3410-0050

E-mail : yschoung@skku.edu
는 인지 기능 저하의 기전과 양상에 관한 연구를 통해 치료 실적과 삶의 질을 함께 제고하기 위한 방안이 활발히 모색되 고 있다.

소아암 환자의 인지 기능 저하는 뇌종양과 같은 중추신경 계 소아암에서 두드러지는 것으로 밝혀졌다. ${ }^{4}$ 뇌종양은 발병 부위와 조직학에 따라 다양한 종류로 나뉘어지는데, 이 중 수 모세포종(medulloblastoma)이 소아기에 가장 빈번히 진단되 는 것으로 알려졌다.5) 수모세포종은 후두와 부근의 소뇌에서 주로 발생하는데, 진행 속도가 빨라 뇌척수액 및 뇌실 침투를 통해 중추신경계나 척수로 전이되는 경우가 많아 상당히 공 격적인 암으로 간주된다. 따라서 외과적 수술 이후에도 재발 이나 병의 진행을 방지를 위해 방사선 조사 및 화학적 항암 요 법을 실시하게 된다. 이는 생존에는 기여하지만 다양한 부정 적 영향을 초래하기도 하는데, 그 중에서도 특히 지능 지수 및 학업 성취도의 저하가 지속적으로 보고되었다. ${ }^{6)}$ 또한 여러 연 
구에서 수모세포종 생존자들이 처리 속도, 주의력, 기억력 같 은 기본적인 인지 기능의 저하도 경험하는 것으로 나타났다.

처리 속도는 한 사람이 인지 조작을 완료하는 전반적인 속 도를 반영하는 기본적인 인지 능력으로, 아동의 처리 속도 향 상은 신경계의 전반적인 성숙과 정밀성을 시사한다. 각업 기 억은 제한된 용량 체계 내에서 정보를 일시적으로 유지하고 조작하는 능력을 일컫는데, 아동의 인지 발달에 대한 경로 분 석결과, 처리 속도의 향상이 작업 기억 발달에 중요한 것으로 밝혀졌다. 나아가 작업 기억은 추론과 같은 고차원의 지적 기 능의 발달을 촉진하여 전반적 지적 능력의 발달에 기여하는 것으로 알려졌다. ${ }^{6)} \mathrm{Palmer}^{8}$ 는 이러한 기존의 인지 이론에 수모 세포종 생존자에 관한 연구결과를 종합하여 소아 수모세포 종의 진단과 치료가 뇌신경 및 인지 기능 발달의 관계에 대한 모델을 제시한 바 있다(Fig. 1). 이는 수모세포종 생존자가 경 험하는 다양한 인지 기능 저하 중에서도 처리 속도에 우선적 인 관심과 개입이 이루어져야 함을 시사한다.

국내에서도 수모세포종 생존자가 치료 이후에 경험하는 부 정적 경험을 최소화하고 삶의 질을 향상시키고자 치료 프로 토콜을 개선하고 생존자에 대한 장기 추적관리 시스템을 도 입하려는 시도가 활발히 이루어지고 있다." 그러나 과거에 급 성 림프구성 백혈병과 같은 혈액암 환자의 인지 기능에 관해 소수의 연구가 이루어졌을 뿐, 전체 소아암 가운데 두 번째로 높은 발병률을 지닌 수모세포종 생존자의 인지 기능에 대한 연구는 전무한 실정이다. ${ }^{10,11)}$ 따라서 본 연구에서는 수모세포 종 환자의 전반적인 인지 기능 양상을 탐색하고, 선행 연구를 통해 밝혀진 바와 같이 처리 속도 및 작업 기억 영역에서의 기 능 손상이 두드러지는지 반복 검증하고자 한다. 또한 비중추 신경계 고형 종양 가운데 소아 발병률이 가장 높다고 알려진 복부 신경모세포종(neuroblastoma) 생존자 집단을 대조군으 로 설정하여, 외과적 수술, 항암제 투여, 자가조혈모세포 이식, 방사선 조사와 같은 보편적인 치료 경험을 통제하여 인지 기

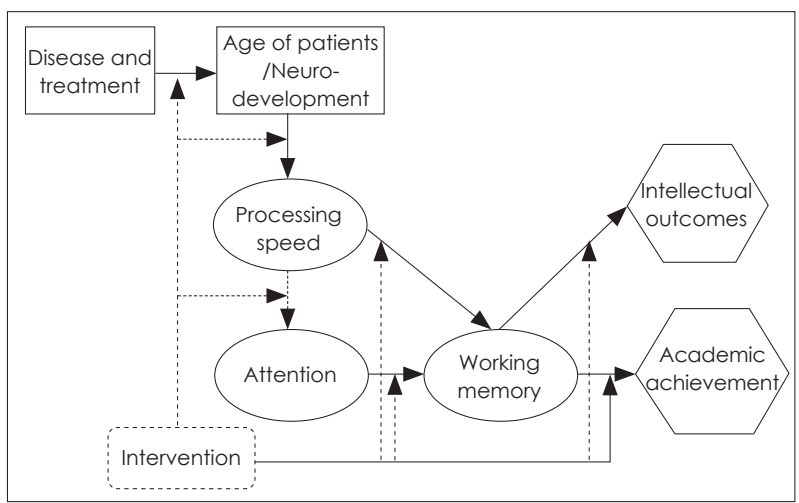

Fig. 1. Conceptual model to understand neurodevelopmental impacts of diagnosis and treatment of pediatric medulloblastoma.
능 양상을 비교하고자 한다. ${ }^{12)}$

\section{방 법}

\section{1. 참가자}

2001년 1월부터 2010년 10월까지 수모세포종 또는 신경모 세포종으로 진단받고 치료 종결 후 외래에서 경과 관찰 중인 환자를 대상으로 하였다. 재발로 인해 저조한 신체 상태를 보 인 수모세포종 환자와 뇌전이가 의심되는 신경모세포종 환자 는 연구에서 제외하였다. 모든 참가자가 임상시험심사위원회 (IRB)의 승인을 받은 소아암 연구에 동의하였다.

\section{2. 치 료}

수모세포종 집단 중 15례에서는 KSPNO-S-051/081 프로 토콜을 적용하여, 절제술, 방사선치료, 고용량 화학요법 및 자 가-말초혈 조혈모세포이식을 적용하였다. 신경모세포종 집단 중 22례에서는 CCG-321P2 및 ICE 프로토콜을 적용하였다. 그 외에 POG-9340 및 COG-A3973 프로토콜을 적용한 경 우가 1례씩 있었다.

방사선 조사를 살펴보면, 수모세포종 집단 중 19례에서 방 사선 조사가 이루어졌으며, 이 중 12례에서 방사선 조사량을 뇌척수 $2,340 \mathrm{cGy}$, 국소 부위 $3,060 \mathrm{cGy}$ 로 동일하게 적용하였 다. 이 외에 파종(seeding) 부위에 $1,440 \mathrm{cGy}$ 를 추가적으로 실 시한 경우가 2례, 국소 부위 조사량을 달리한 경우가 5례였다. 신경모세포종 집단 중 22례에서 방사선 조사가 이루어졌으며, 전신 조사 $999 \mathrm{cGy}$ 와 국소 조사 1,500 3,060Gy를 병행한 경 우가 12례, 국소 조사 2,160 2,700cGy만 실시한 경우가 6례, 전신 조사만 시행한 경우가 4례였다.

\section{3. 방 법}

임상심리학자가 참가자에게 개별적으로 한국 웩슬러 아동용 지능 검사(Korean version of Wechsler Intelligence Scales for Children, K-WISC-III)를 실시하였다. 이 검사는 언어성 지능을 평가하는 기본지식(information), 공통성(similarity), 산수(arithmetic), 어휘(vocabulary), 이해(comprehension), 숫자(digit span) 소검사와 동작성 지능을 평가하는 빠진 곳 찾 기(picture completion), 기호쓰기(coding), 차례 맞추기(picture arrangement), 토막짜기(block design), 모양 맞추기(object assembly) 소검사로 구성되어 있다. 기존 연구에서도 기 호쓰기 소검사는 처리 속도 평가에, 숫자 소검사는 주의력 및 작업 기억의 평가에 사용된 바 있다. ${ }^{13-15)}$

각 소검사의 원점수는 연령별 규준에 따라 평균 10 , 표준편 차 3 인 환산점수로 변환되며, 환산점수 16 이상은 최우수, 14 15는 우수, 12 13은 평균 상, 9 11은 평균, 7 8은 평균 하, 5 
6 은 경계선, 4 이하는 정신지체 수준으로 분류된다. 환산점수 의 합산을 토대로 평균 100 , 표준편차 15 인 전체 지능(full scale IQ), 언어성 지능(verbal IQ), 동작성 지능(performance IQ) 지수가 산출된다. 지능 지수는 범위에 따라 130점 이상은 최우수(백분위 98 100\%ile), 120 129점은 우수(91 97\%ile), 110 119점은 평균 상(76 90\%ile), 90 109점은 평균(25 75\% ile), 80 89점은 평균 하(10 24\%ile), 70 79점은 경계선(3 9\% ile), 69점 이하는 정신지체(0 2\%ile) 수준으로 분류된다.

\section{4. 통계 분석}

통계 분석은 SPSS for Windows(version 17.0)를 사용하였 다. 먼저 표본수가 적은 관계로 진단 및 평가시의 연령, 진단 후 경과 시간, $\mathrm{K}-\mathrm{WISC}-\mathrm{III}$ 에서 획득한 지능 지수와 소검사별 환산 점수가 정규성을 충족하는지 알아보고자 KolmogorovSmirnov 검정을 실시하였다. 또한 진단시의 연령, 진단 이후 경과 시간, 평가시의 연령 성별 및 치료 관련 변인의 적용 여부 에서 두 집단 간 차이가 나타나는지 알아보고자 $\chi^{2}$ 검증을 실
시하였다. 또한 수모세포종 생존자의 인지 기능 저하에 영향 을 미치는 것으로 알려진 진단시 연령과 진단 후 경과 시간에 서 집단간 차이가 유의미한 것으로 나타나 두 변인을 공변량 으로 설정한 후 두 집단 간의 차이에 대한 공변량분석(ANC$\mathrm{OVA})$ 을 시행하였다. ${ }^{12}$ 결과 분석시에는 p값이 .05 미만일 때 통계적으로 유의미한 차이로 간주하였다.

\section{결 과}

참가자는 수모세포종 집단이 21명, 신경모세포종 집단이 24 명이었다(Table 1). 진단시 연령의 평균은 수모세포종 집단이 7.94세, 신경모세포종 집단이 3.60세로 집단 간 차이가 유의 미하였다( $\mathrm{p}=.000)$. 진단 후 경과 시간은 수모세포종 집단이 평 균 3.56년, 신경모세포종 집단이 5.09년으로 유의미한 차이를 보였다( $\mathrm{p}=.034)$. 집단별 성별 분포는 수모세포종 집단이 남아 17 명, 여아 4 명, 신경모세포종 집단이 남아 17 명, 여아 7 명으

Table 1. Comparison of clinical characteristics and treatment methods of subjects $(\mathrm{N}=45)$

\begin{tabular}{|c|c|c|c|c|}
\hline & Medulloblastoma $(\mathrm{N}=21)$ & Neuroblastoma $(\mathrm{N}=24)$ & t & $n$ \\
\hline & Mean (SD) & Mean (SD) & 1 & p \\
\hline Age at diagnosis (years) & $7.94(3.68)$ & $3.60(2.32)$ & 4.652 & .000 \\
\hline Age at evaluation (years) & $11.52(2.67)$ & $8.72(2.29)$ & 3.785 & .000 \\
\hline \multirow[t]{2}{*}{ Time since diagnosis (years) } & $3.56(2.84)$ & $5.09(1.46)$ & -2.319 & .034 \\
\hline & $\mathrm{N}(\%)$ & $\mathrm{N}(\%)$ & $\chi^{2}$ & $\mathrm{p}$ \\
\hline Sex & & & .621 & .431 \\
\hline Male & $17(81.0)$ & $17(70.8)$ & & \\
\hline Female & $4(19.0)$ & $7(29.2)$ & & \\
\hline \multicolumn{5}{|l|}{ Treatment } \\
\hline Chemotherapy & $21(100.0)$ & $24(100.0)$ & - & - \\
\hline Pre-RT/OP+HDCT & $20(95.2)$ & $21(87.5)$ & & \\
\hline Pre-RT/OP & $1(4.8)$ & $3(12.5)$ & & \\
\hline Resection & $21(100.0)$ & $23(95.8)$ & .895 & .344 \\
\hline Gross total resection & $12(57.1)$ & $12(50.0)$ & & \\
\hline Subtotal resection & $9(42.9)$ & $11(45.8)$ & & \\
\hline Irradiation & $19(90.5)$ & $22(91.7)$ & .020 & .889 \\
\hline CSI+LF RT & $18(85.7)$ & $0(0.0)$ & & \\
\hline CSI & $1(4.8)$ & $0(0.0)$ & & \\
\hline $\mathrm{TBI}+\mathrm{LF}$ RT & $0(0.0)$ & $11(45.8)$ & & \\
\hline LF RT & $0(0.0)$ & $8(33.3)$ & & \\
\hline TBI & $0(0.0)$ & $3(12.5)$ & & \\
\hline Auto-PBSCT & $20(95.2)$ & $21(87.5)$ & .828 & .363 \\
\hline Residual tumor & $6(28.6)$ & $2(8.3)$ & 2.779 & .249 \\
\hline$<1.5 \mathrm{~cm}^{2}$ & $3(14.3)$ & - & & \\
\hline$\geq 1.5 \mathrm{~cm}^{2}$ & $3(14.3)$ & - & & \\
\hline Seeding & $7(33.3)$ & $21(87.5)$ & 13.980 & .000 \\
\hline Complication & $4(19.0)$ & $2(8.3)$ & 9.474 & .002 \\
\hline Relapse & $2(9.5)$ & $1(3.6)$ & .517 & .472 \\
\hline
\end{tabular}

Pre-RT/OP : previous radiotherapy and operation (resection), HDCT : high-dose chemotherapy, CSI : cerebrospinal irradiation, LF RT : local field radiotherapy, TBI : total body irradiation, Auto-PBSCT : autologous peripheral blood stem cell transplantation, SD : standard deviation 
Table 2. ANCOVA of IQ and subtest scores

\begin{tabular}{|c|c|c|c|c|c|}
\hline & $\begin{array}{c}\text { Medulloblastoma } \\
(\mathrm{N}=21)\end{array}$ & $\begin{array}{c}\text { Neuroblastoma } \\
(\mathrm{N}=24)\end{array}$ & $\begin{array}{c}\text { Age at } \\
\text { diagnosis }\end{array}$ & $\begin{array}{c}\text { Time since } \\
\text { diagnosis }\end{array}$ & $\begin{array}{l}\text { Kind of } \\
\text { tumor }\end{array}$ \\
\hline & Mean (SD) & Mean (SD) & $\mathrm{p}$ & $\mathrm{p}$ & $\mathrm{p}$ \\
\hline Full scale IQ & $79.81(19.97)$ & $93.50(17.09)$ & .146 & .022 & .074 \\
\hline Verbal IQ & $85.48(20.22)$ & $96.79(16.76)$ & .257 & .036 & .112 \\
\hline Performance IQ & $77.29(18.39)$ & $91.25(18.20)$ & .139 & .033 & .080 \\
\hline Information & $7.81(3.97)$ & $9.75(3.12)$ & .255 & .023 & .135 \\
\hline Similarity & $8.52(2.66)$ & $9.55(3.47)$ & .185 & .796 & .956 \\
\hline Arithmetic & $7.95(3.92)$ & $8.92(2.87)$ & .406 & .090 & .046 \\
\hline Vocabulary & $8.05(4.08)$ & $10.04(2.81)$ & .040 & .019 & .350 \\
\hline Comprehension & $7.29(2.65)$ & $9.21(2.81)$ & .031 & .038 & .279 \\
\hline Digit span & $7.05(3.41)$ & $9.46(3.44)$ & .335 & .906 & .015 \\
\hline Picture completion & $9.05(2.48)$ & $9.67(3.70)$ & .621 & .638 & .299 \\
\hline Coding & $4.76(3.40)$ & $8.71(3.47)$ & .102 & .408 & .034 \\
\hline Picture arrangement & $6.90(3.10)$ & $8.08(2.93)$ & .023 & .001 & .489 \\
\hline Block design & $7.43(3.66)$ & $9.42(3.57)$ & .519 & .095 & .111 \\
\hline Object assembly & $7.36(3.67)$ & $8.06(2.19)$ & .155 & .035 & .774 \\
\hline
\end{tabular}

SD : standard deviation

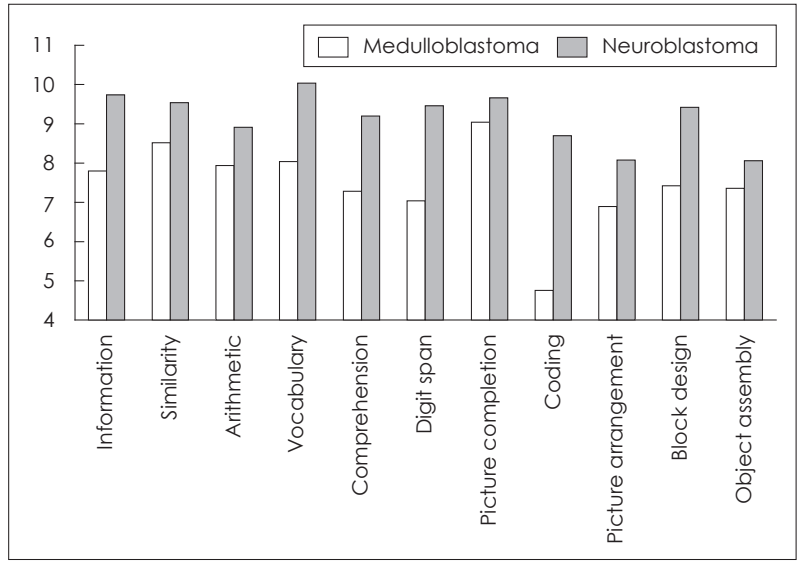

Fig. 2. Subtest scores of medulloblastoma and neuroblastoma patients.

로 차이가 나타나지 않았다(p=.431). 원발 병소를 살펴보면, 수 모세포종은 소뇌 16례, 제4뇌실 5례였고, 신경모세포종은 부 신 18례, 후복막강 4례, 종격동 2례였다.

인지 기능 양상에 대한 공변량 분석결과는 Table 2 와 Fig. 2에 제시하였다. 먼저 전반적 인지 기능을 살펴보면, 수모세포 종 집단은 전체 지능 79.81 , 언어성 지능 85.48 , 동작성 지능 77.29로 평균 하-경계선 수준의 낮은 점수를 획득하였으며, 특히 동작성 지능에서 저조한 수행을 보였다. 반면, 신경모세 포종 집단은 전체 지능 93.50 , 언어성 지능 96.79 , 동작성 지능 91.25 로 평균 수준의 대체로 고른 수행을 보였다. 공변량 분석 결과 전체 지능, 언어성 지능, 동작성 지능에서 집단 간에 유의 미한 차이는 없는 것으로 나타났다 $(\mathrm{p}<.05)$.

개별 소검사 수준에서는 진단시 연령과 진단 이후 경과 시
간을 통제했을 때, 산수, 숫자, 기호쓰기 소검사에서만 집단 간 의 차이가 유의미하였다 $(\mathrm{p}<.05)$. 특히 기호쓰기 소검사에서 수모세포종 집단은 평균 4.76점을 획득하여 처리 속도가 현저 히 저하된 것으로 나타났다. 또한 주의력 및 작업 기억을 측정 하는 것으로 알려진 숫자 및 산수 소검사에서 수모세포종 집 단이 낮은 수행을 보였다.

\section{고 찰}

뇌신경 발달에 영향을 미치는 요소를 통제한 후에도 수모 세포종 집단이 처리 속도, 주의력 및 작업 기억을 측정하는 소 검사에서 유의미하게 낮은 수행을 보인 것은, 뇌종양의 발생 과 치료가 뇌의 정상 발달을 저해하며 이것이 기본 인지 기능 인 처리 속도와 작업 기억의 저하를 유발하여 이것이 향후 전 반적 인지 기능의 발달의 저하로 이어진다는 선행 연구결과 를 뒷받침하는 것으로 해석할 수 있다.,16-18) 이와 관련해 방사 선 치료가 뇌의 수초화(myelination)를 방해하여 정보 처리 속도를 지연시킨다는 뇌신경적 기전이 일련의 연구를 통해 밝 혀진 바 있다. ${ }^{18,19}$ 또한 Palmer 등인 종단 연구를 통해 수모 세포종 환자가 지능 검사에서 획득하는 원점수는 상승하지만 이것이 발달 과정에서 평균적으로 기대되는 양에 미치지 못 하여 연령 규준에 의해 환산된 상대적 위치인 지능 지수가 낮 아진다는 점을 입증하였다. 이처럼 처리 속도의 저하는 정보 의 원활한 습득과 인출에 어려움을 야기하여 결과적으로 전 반적 인지 기능의 저하로 이어질 수 있다.

본 연구가 가지는 의의를 연구결과와 관련지어 생각해 볼 
수 있다. 가장 빈발하는 중추신경계 고형 종양인 수모세포종 과 비중추신경계 고형 종양인 신경모세포종 생존자를 대상으 로 치료 종결 후 인지 기능을 살펴본 것은 치료 성과를 삶의 차원에서 보다 광범위하게 이해하고 소아암 생존자들이 일반 적으로 경험할 것으로 예상되는 어려움을 예측하는데 기여할 것으로 생각된다. 또한 지능이라는 전반적 인지 기능의 양상 의 기술에 그치지 않고, 뇌신경 발달에 관한 이론을 바탕으로 소검사 프로파일 분석을 통해 처리 속도와 주의력 및 작업 기 억의 저하 가능성과 이것이 전반적 지적 능력의 발달에 미치 는 영향을 조명했다는 점도 향후 발병 및 치료의 부정적 영향 을 최소화하고 적절한 개입 시점과 방법을 강구하는데 도움 이 될 수 있다.

다음으로 본 연구의 한계점 및 후속 연구 방향을 위한 몇 가지 논의를 하고자 한다. 본 연구에서 처리 속도 측정을 위해 기호쓰기 소검사를 사용하였는데, 미세 운동 협응 능력이 이 검사의 수행에 영향을 미칠 수 있어 그 결과를 처리 속도의 저 하로 해석하는데 주의가 필요하다. 따라서 차후에는 연구 설 계시 인지 기능으로서의 처리 속도를 보다 다양한 방법으로 평 가하는 것이 필요하다. 또한 본 연구는 처리 속도에 상당한 영 향을 미치는 것으로 알려진 방사선 조사를 적절히 통제하지 못 했다는 점에서 한계를 갖는다. 선행 연구에서는 신경모세포종 과 같은 비중추신경계 고형 종양 집단을 임상 대조군으로 설 정할 경우에 화학적 항암 요법만 실시했거나 중추 신경계에 방사선 조사가 이루어지지 않은 환자를 대상으로 하였다. ${ }^{12)}$ 그 러나 본 연구에서는 대조군의 절반 이상이 전신 방사선 조사 를 시행받았는데, 뇌종양 환자에 대한 연구에서 전신 방사선 조사는 전두개 방사선 조사와 같은 수준의 주의력 저하를 야 기하는 것으로 보고된 바 있어, 향후에는 대조군 설정시 관련 변인을 보다 엄격히 통제하는 것이 요망된다. ${ }^{21)}$

의학의 발전에 힘입어 소아암 치료의 핵심이 생존 및 재발 방지에서 건강 관리 및 삶의 질 향상 차원으로 발전해가고 있 다. 이 시점에서 소아암 생존자의 인지 기능에 관심을 가지고 회복과 유지를 도모하는 것은 치료에서 상당히 중요한 부분 을 차지한다. 본 연구가 인지 기능에 대한 치료자의 관심을 제 고하고 소아암 생존자에 대한 개입 방안을 마련하는 작은 계 기가 될 수 있기를 희망한다.

중심 단어 : 소아암 - 인지 기능 - 처리 속도 - 작업 기억력 · 수모 세포종·신경모세포종.

\section{References}

1) Yu ES. Psychological intervention of cancer patients. Proceedings of Korean psychology association annual conference; 2008 Aug 20-
22;Seoul, Korea: Korean psychology association;2008. p.488-489.

2) Fuemmeler BF, Elkin TD, Mullins LL. Survivors of childhood brain tumors: behavioral, emotional, and social adjustment. Clin Psychol Rev 2002;22:547-585.

3) Mulhern RK, Palmer SL. Neurocognitive late effects in pediatric cancer. Curr Probl Cancer 2003;27:177-197.

4) Moore BD 3rd. Neurocognitive outcomes in survivors of childhood cancer. J Pediatr Psychol 2005;30:51-63.

5) Blaney SM, Kun LE, Hunter J, Rorke-Adams LB, Lau C, Strother D, et al. Tumors of the central nervous system. In: Piaao PA, Poplock DG, editors. Principles and practice of pediatric oncology. 5th ed. New York: Lippincott Williams \& Wilkins Co;2006. p.786-864.

6) Reeves CB, Palmer SL, Reddick WE, Merchant TE, Buchanan GM, Gajjar A, et al. Attention and memory functioning among pediatric patients with medulloblastoma. J Pediatr Psychol 2006;31:272-280.

7) Kail R. Processing speed, speech rate, and memory. Dev Psychol 1992;28:899-904.

8) Palmer SL. Neurodevelopmental impact on children treated for medulloblastoma: a review and proposed conceptual model. Dev Disabil Res Rev 2008;14:203-210.

9) Park HJ, Nam BH, Yun YH, Yang WJ, Kang HJ, Shin HY, et al. Establishment of Korean childhood cancer survivor cohort and longterm follow-up system. Clin Pediatr Hematol Oncol 2007;14:1-42.

10) Choi JE, Shin HY, Kim IO, Yeon KM, Chae IY, Cho SC. Effects of central nervous system irradiation on neuropsychologic functioning in long-term survivors of childhood acute lymphoblastic leukemia. Cancer Res Treat 2007;50:182-189.

11) Kim GH, Kook H, Baek HJ, Han DK, Song ES, Jo YK, et al. Comparison of growth and neuropsychological function after treatment for hematologic and oncologic diseases in monozygotic twins. Korean J Pediatr 2007;50:182-189.

12) Mabbott DJ, Penkman L, Witol A, Strother D, Bouffet E. Core neurocognitive functions in children treated for posterior fossa tumors. Neuropsychology 2008;22:159-168.

13) Stargatt R, Rosenfeld JV, Maixner W, Ashley D. Multiple factors contribute to neuropsychological outcome in children with posterior fossa tumors. Dev Neuropsychol 2007;32:729-748.

14) Brière ME, Scott JG, McNall-Knapp RY, Adams RL. Cognitive outcome in pediatric brain tumor survivors: delayed attention deficit at long-term follow-up. Pediatr Blood Cancer 2008;50:337-340.

15) Mabbott DJ, Spiegler BJ, Greenberg ML, Rutka JT, Hyder DJ, Bouffet $\mathrm{E}$. Serial evaluation of academic and behavioral outcome after treatment with cranial radiation in childhood. J Clin Oncol 2005;23: 2256-2263.

16) Fry AF, Hale S. Relationships among processing speed, working memory, and fluid intelligence in children. Biol Psychol 2000;54:1-34.

17) Kieffer-Renaux V, Bulteau C, Grill J, Kalifa C, Viguier D, Jambaque I. Patterns of neuropsychological deficits in children with medulloblastoma according to craniospatial irradiation doses. Dev Med Child Neurol 2000;42:741-745.

18) Schatz J, Kramer JH, Ablin A, Matthay KK. Processing speed, working memory, and IQ: a developmental model of cognitive deficits following cranial radiation therapy. Neuropsychology 2000; 14:189-200.

19) Fry AF, Hale S. Processing speed, working memory, and fluid intelligence: evidence for a developmental cascade. Psychol Sci 1996; 7:237-241.

20) Palmer SL, Goloubeva O, Reddick WE, Glass JO, Gajjar A, Kun L, et al. Patterns of intellectual development among survivors of pediatric medulloblastoma: a longitudinal analysis. J Clin Oncol 2001; 19:2302-2308.

21) Leiper AD. Late effects of total body irradiation. Arch Dis Child 1995;72:382-385. 